\title{
Beyond National Networking: International Research and Teaching Activities in Biotechnology at the University of Applied Sciences Wädenswil
}

\author{
Karin Kovar ${ }^{\star a}$, Radka Strnadováac, Maggi Lussi Bell ${ }^{\mathrm{b}}$, and Tobias Merseburger ${ }^{\mathrm{a}}$
}

\begin{abstract}
The Institute of Biotechnology (formerly the Department of Biotechnology) at the Zurich University of Applied Sciences in Wädenswil has established itself internationally. Building-up expertise in complementary research fields as well as an orientation to German-speaking and/or small European countries have proved to be successful strategies to continually increase the amount of external funding for R\&D projects (up to CHF 1.5 million expected in 2007). A bottom-up approach facilitated by lecturers' and students' individual initiatives has taken advantage of European and/or Swiss programmes (e.g. ERASMUS, IAESTE, Eureka, CTI and SVC). The international activities described have improved the quality of teaching and promoted the development of communication skills, enabling students to be better prepared for careers in international interdisciplinary teams. These activities have also assisted in the ongoing transformation of the study programmes to meet the requirements of the Bologna Declaration aiming at creating convergence in the European higher education sector.
\end{abstract}

Keywords: Biotechnology · BioTech conference · Foreign-language proficiency · International cooperations . Student mobility

\section{Internationalisation in Teaching and Research}

The study programme in biotechnology at the University of Applied Sciences (UAS) Wädenswil (part of the Zurich University of Applied Sciences (ZHAW) from September 2007) was launched in 1994, having been designed in close cooperation with the biotechnological industry to fulfil needs

\footnotetext{
${ }^{*}$ Correspondence: Prof. Dr. K. Kovar ${ }^{\mathrm{a}}$

Tel.: +41447899733

E-Mail:k.kovar@hsw.ch

anstitute of Biotechnology

Zurich University of Applied Sciences

Grüental

Postfach 335

$\mathrm{CH}-8820$ Wädenswil, Switzerland

bDepartment of Humanities and Natural Sciences

Zurich University of Applied Sciences

Wädenswil

Institute of Education

University of Zurich

Zurich, Switzerland
}

arising in the manufacture of pharmaceuticals. As biotechnology is a global industry, the introduction of this study programme in Wädenswil was also instrumental in the institution's change from a higher technical college (founded in 1970) to the present University of Applied Sciences, which is internationally recognised in the field of Life Sciences. At present, the main activities which facilitate both cross-border mobility and know-how transfer are:

i) adapting programmes in line with recent educational policy (i.e. IAESTE student exchange, ERASMUS student and teacher exchange, implementation of the Bologna guidelines including ECTS),

ii) implementing changes in language course regulations (i.e. English has been compulsory for all students since 2005; other language courses, including German as a foreign language, are optional), and

iii) striving for co-operations in research (e.g. joint projects as part of Eureka or the EU-Framework programme, and active participation in professional associations abroad such as the European Federation of Biotechnology (EFB), Dechema (Germany), Swiss-Czech and
Swiss-Japanese biotechnology associations) as well as organising international conferences.

With regard to both student exchange and research activities, the Institute of Biotechnology (formerly the Department of Biotechnology at UAS Wädenswil) operates worldwide, even though most of its current international co-operations are with German-speaking countries (Fig. 1).

Since an International Relations Office and structures for the development of research strategies ${ }^{[1]}$ are still in the process of being set up at the newly established Zurich University of Applied Sciences (ZHAW), the opportunity should now be taken to tailor the supporting structures to fulfil real needs. As a basis for this, the current international activities of the Institute of Biotechnology (and, where appropriate, of the whole Wädenswil campus) are summarised in this paper. Since most research activities at universities of applied sciences are driven by an existing application or practice, both the successful discipline-specific and institution-specific approaches to crossing borders described in this paper might differ from those suitable for other main fields of study and/or from the approaches of the ETH and universities. 


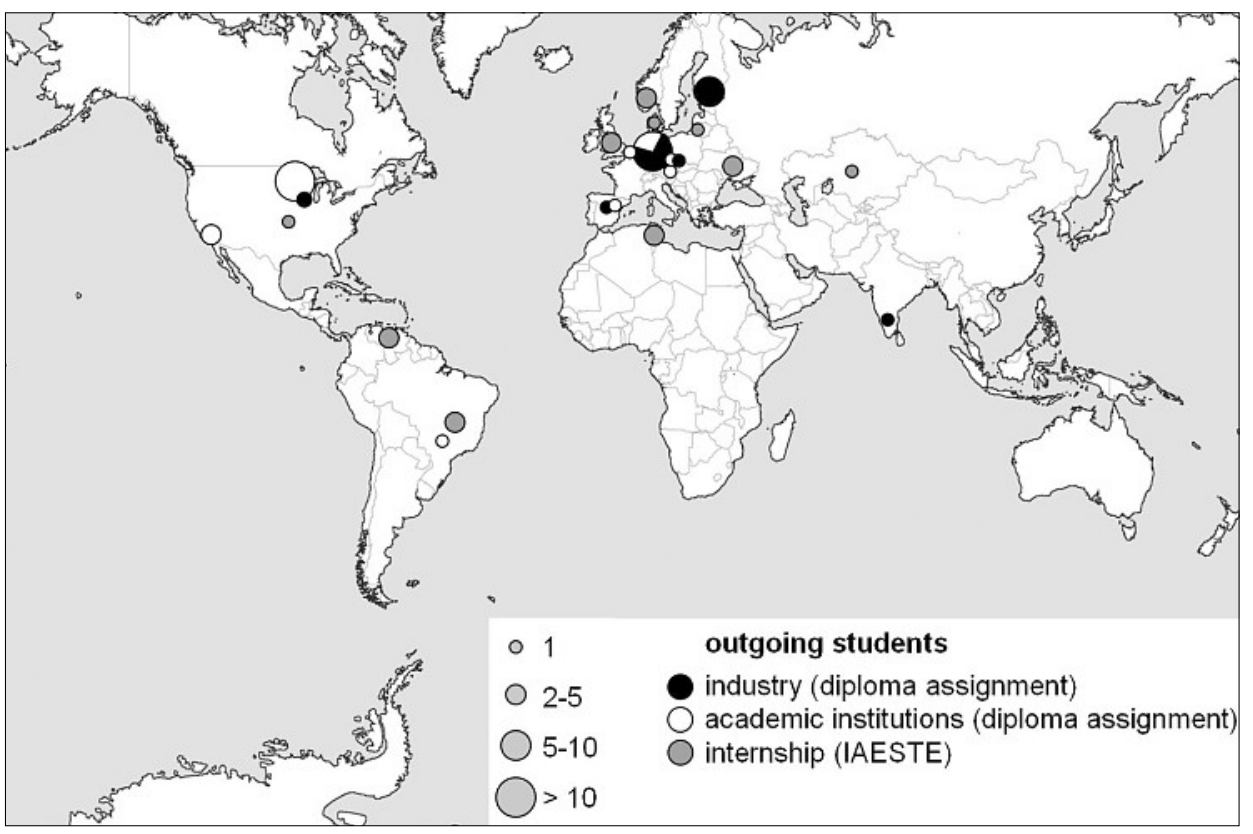

Fig. 1. Geographical locations of sites of international cooperation (with the Institute of Biotechnology)

Notwithstanding the relatively small percentage of UAS students opting for Life Sciences, which has decreased from $4.65 \%$ to $2.44 \%{ }^{2]}$ over the last six years, the biopharmaceutical industry in Switzerland is growing rapidly. ${ }^{[3,4]}$ Improved promotion of this field of study (both nationally and internationally) is therefore required in order that the demand for graduates might be met.

\section{Ways of Setting up Successful International Co-operations}

Participating in mobility schemes, conducting research projects, and organising scientific conferences are considered essential to the profitable and sustainable cross-border activities of the Institute of Biotechnology. The resources and framework which facilitates international cooperation at the UAS Wädenswil have been set up gradually over time (Table).

A bottom-up approach facilitated by lecturers' and students' individual initiatives has benefited from European and/or Swiss programmes (e.g. ERASMUS, IAESTE, Eureka, CTI and SVC). In order to promote its activities, the Institute of Biotechnology (formerly the Department of Biotechnology) is frequently present at trade fairs (e.g. Biotechnika, ILMAC, Achema). This is made possible only by the support of Biotechnet Switzerland, http://www.bio technet.ch, and the public relations office at the UAS Wädenswil, participation in trade fairs being too cost- and time-intensive for the Institute to finance independently. Biotechnet also helps arrange and conduct courses (e.g. Summer School in Advanced

Table. Development of international activities from a chronological perspective (at the Institute of Biotechnology)
Year

1993

1994

1994

1996

1996

1997

1998

1998

1999

1999

2001

2002

2003

2003

2005

2006

2007

2007

2008

\section{Steps towards international} partnerships

First project with an international university partner

Biotechnology study programme launched

First project with an international partner from industry

First bilateral agreement with a European university

First diploma assignment conducted abroad

First Cambridge exams accomplished

Foundation of University of Applied Sciences Zurich

Foundation of Mobility Office at UAS Wädenswil

First EUREKA Project

First e-learning project in scope of Swiss Virtual Campus

First bilateral agreement with an American university

Joining ERASMUS

English as a compulsory subject

French and/or Spanish as optional subjects

First Bachelor degree programmes, ECTS implementation

German as a foreign language

First application as main participant in scope of European Framework Programmes

Foundation of the new Zurich University of Applied Sciences ZHAW

Expected start of the Master's programme in Life Sciences
Biotechnology in cooperation with the University of Palermo, Italy; continuous education courses for international enterprises such as Roche and Novartis) ${ }^{[5]}$ and co-supports the biotechLAB e-learning platform, http://www.biotechLAB.net. As publicising the findings of applied industry projects in reviewed journals is not always straightforward, the bulletin Transfer (first published in $2004^{[6]}$ ) serves as a good means of disseminating information on Wädenswil's R\&D activities.

At present, the administrative staff at the UAS Wädenswil supports the international activities by dealing with the ERASMUS student exchange programme (including finding accommodation) as well as by organising registration, social programmes and exhibitions at Wädenswil's scientific conferences. However, in spite of this assistance, active cross-border cooperation still significantly increases the administrative load of the lecturers involved.

\subsection{Mobility and Language \\ Proficiency in Education}

As the opportunities for everyday intercultural exchanges on the Wädenswil campus are limited, it was mainly the students desire to further their language skills and to gain experience abroad that prompted joining the ERASMUS programme in 2002. Around $27 \%$ of biotechnology students (2002-2006) have taken advantage of this to do their diploma assignments in a foreign country. To date, the UAS Wädenswil has signed 35 cooperation contracts with universities from 12 countries (Fig. 2). Of these 35 contracts, $23(65.7 \%)$ are with institutions in German-speaking countries. The Institute of Biotechnology initiated and is actively involved in $48 \%$ (17) of these contracts in seven different countries (i.e. Germany, Belgium, Spain, Finland, Italy, Austria and the Czech Republic). Surprisingly, ERASMUS grants are more frequently used by students from foreign universities coming to Wädenswil than by Wädenswil students crossing borders (Fig. 3). However, quite a number of UAS Wädenswil students have been abroad as a result of bilateral, nonERASMUS agreements (e.g. University of Minnesota, USA, through an agreement initiated in 2001; VVT, Espoo, Finland since 1993) or due to their finding a position in a foreign company or research institute.

Proficiency in foreign languages, especially in English, is a prerequisite for operating on an international basis. For this reason, endeavours to improve language skills are focussed not only on the students themselves but also extend to providing language support to lecturers and scientists (e.g. on an individual basis when acquiring new projects/contacts and publishing research results). Since the implementation of the Bologna Process in 2005, ${ }^{[7]}$ English is 


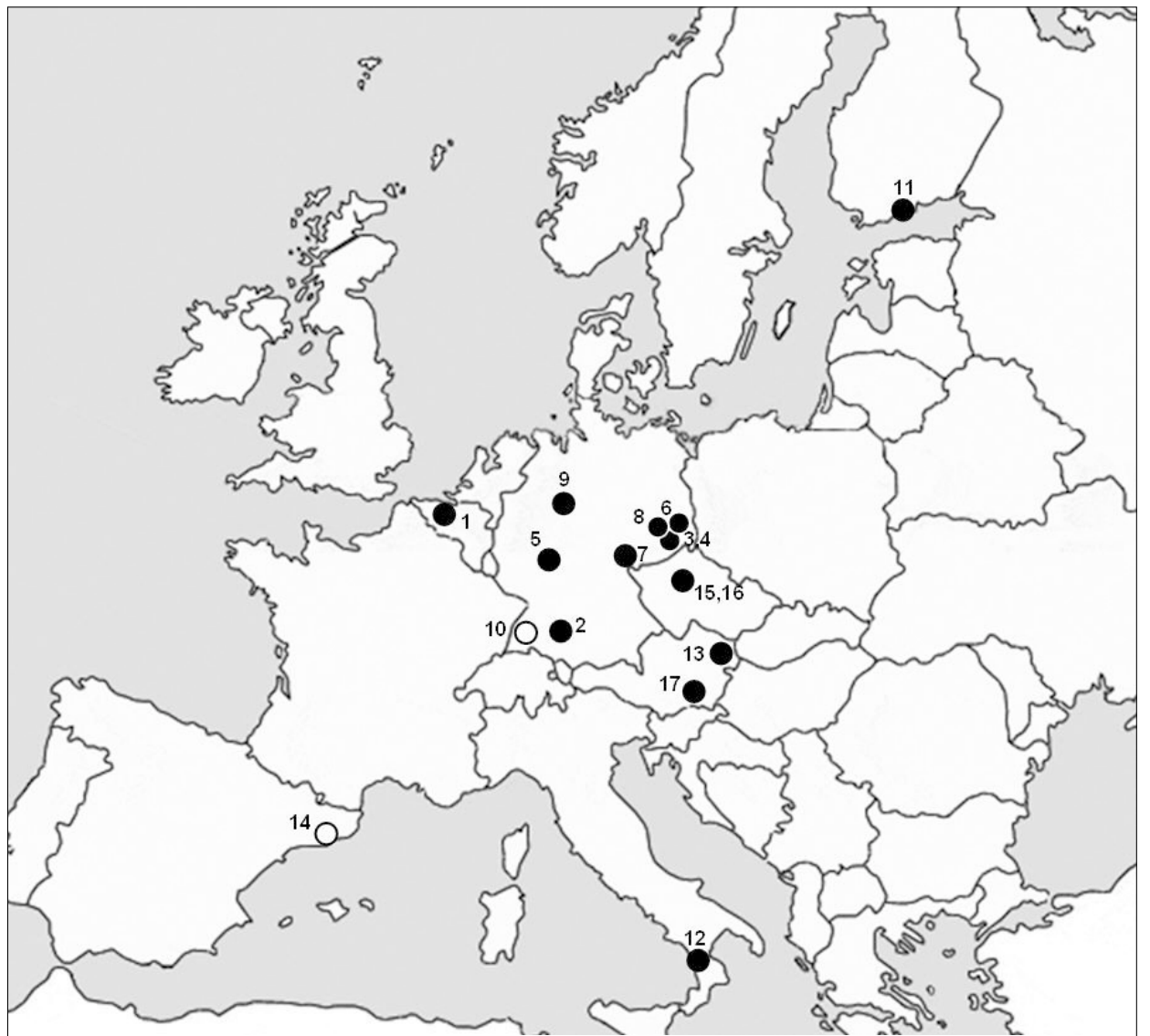

Fig. 2. Partners in ERASMUS (with the Institute of Biotechnology).

Closed circles - ERASMUS contracts concluded. Open circles - ERASMUS contracts not yet signed. Although there have already been numerous student exchanges, administrative matters are still under negotiation. 1. Ghent University, B; 2. UAS Biberach, D; 3. UAS Dresden, D; 4. Technical University Dresden, D; 5. UAS Giessen-Friedberg, D; 6. UAS Lausitz; 7. UAS Jena; 8. UAS Anhalt, Bernburg, Köthen, Dessau, D; 9. Wilhelms-University Münster, D; 10. UAS Furtwangen, D; 11. University of Helsinki, Fl; 12. University of Calabria, IT; 13. fh campus \& BOKU Vienna, A;14. University of Barcelona, ES; 15. Inst. of Chemical Technology Prague, CZ; 16. Technical University Prague, CZ; 17. Technical University Graz, A

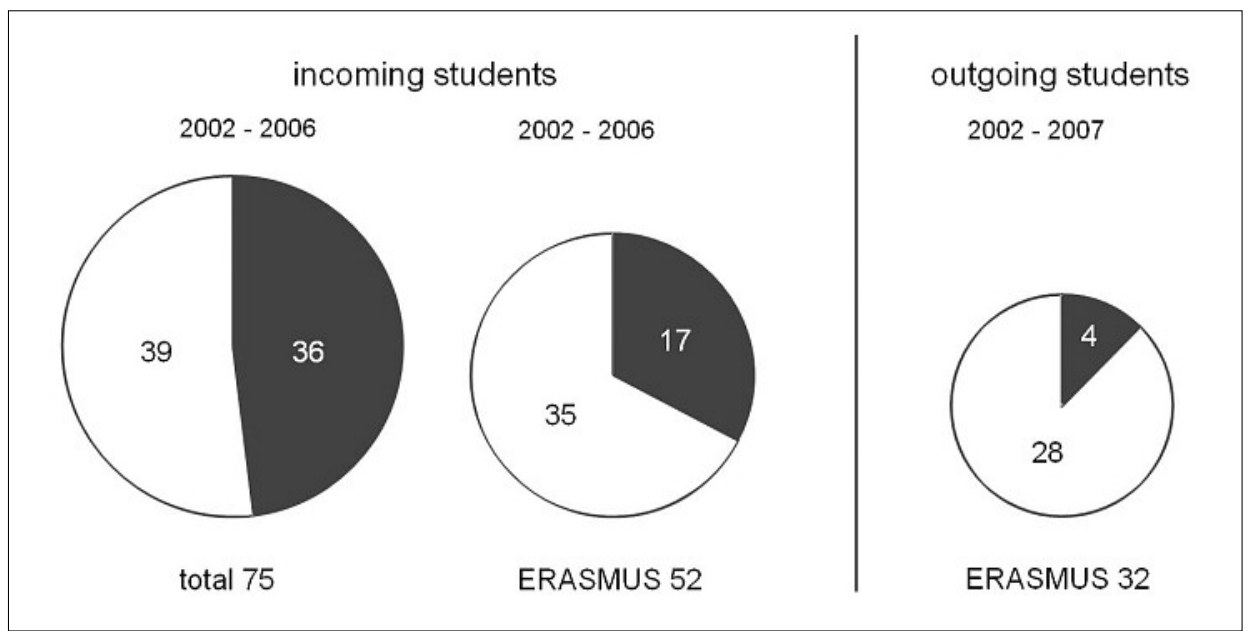

Fig. 3. Student mobility. The black sector indicates the number of students at the Institute of Biotechnology, the white sector the total number of students at the UAS Wädenswil.

compulsory for all Biotechnology students at the UAS Wädenswil who do not have an internationally recognised qualification equivalent to $\mathrm{C} 2$ (Mastery) on the Council of Europe's Common European Framework of Reference for Languages. There are also supplementary courses to prepare students for external internationally recognised ex- ams (University of Cambridge ESOL examinations), which started in 1996 and boast a relatively high success rate $(83 \%)$. It is noted that, although the number of students at Wädenswil has been steadily increasing over the last eight years (e.g. in the third semester from 70 in 1999 to approx. 220 in $2006^{[8]}$ ), the number of enrolments for
Cambridge exams has stagnated at about 50 students per annum (Fig. 4). In addition to English, French and Spanish have been offered as optional languages since 2003 and courses in German as a foreign language for non-native speakers (both staff and students) since 2006. Although English is extensively used as a lingua franca in international business and academic settings, knowledge of other languages together with the associated cultures is clearly advantageous when dealing with partners from non-English speaking countries.

\subsection{From Serving Industry to an International Research Network}

Each of the eleven sections within the Institute of Biotechnology maintains its own individual international contacts to research groups in its particular field of interest. Building-up expertise in complementary research fields as well as an orientation to German-speaking and/or small European countries has proved to be a successful strategy to continually increase the amount of external funding for $R \& D$ projects (up to CHF 1.5 million expected in 2007, Fig. 5).

A good example of developing such an international cooperation network is provided by the Bioprocess Technology group. Since 1999 it has been cooperating on a long-term basis with Lonza Ltd, $[9,10]$ a globally active Swiss company with its headquarters in Basel, its largest production and research site in Visp, and an important microbial production site in the Czech Republic. After the first contacts with Lonza at scientific conferences, an applied research project with their R\&D department in Visp, supported by the Commission of Technology and Innovation (CTI project number 3596.2), was launched in 2002. The project sought to improve productivity and included analysing the available process data, assessing potential for improvement, and proposing process changes. This led to an enhancement of production efficiency by more than $25 \%,{ }^{111]}$ a result which also directly (and positively) impacted on the Lonza production site for microbial processes in Kourim, Czech Republic. Production at this site has gradually been increased, with Lonza recently investing EUR 31.5 million into a new manufacturing project there. ${ }^{[12]}$

Some six years after the first contact with Lonza, further joint projects have been initiated under the Eureka umbrella (project numbers CTI 7403.3, CTI 8599.1 and $E ! 3415)$, which have included the participation of local Czech university. Thus, from preliminary mutual interest in a research topic, contact was made with the Institute of Chemical Technology in Prague. In addition, several other Swiss-Czech (educational) activities have resulted, such as jointly organising conferences, exchanging 


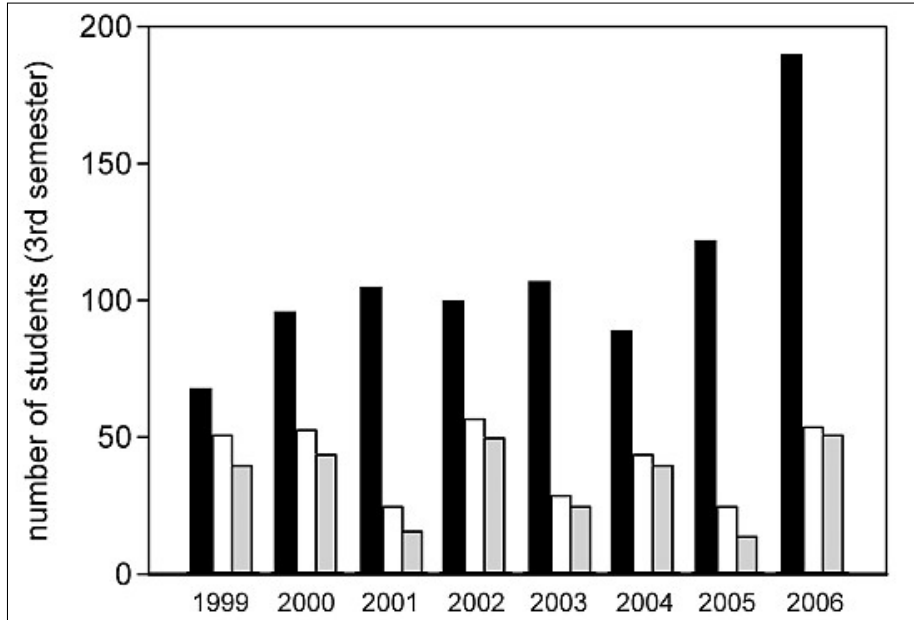

Fig. 4. Development of student numbers on Cambridge courses and exam enrolment. Black bars indicate the total numbers of students at the UAS Wädenswil, white bars the numbers of students taking Cambridge exams, and grey bars their success rates.

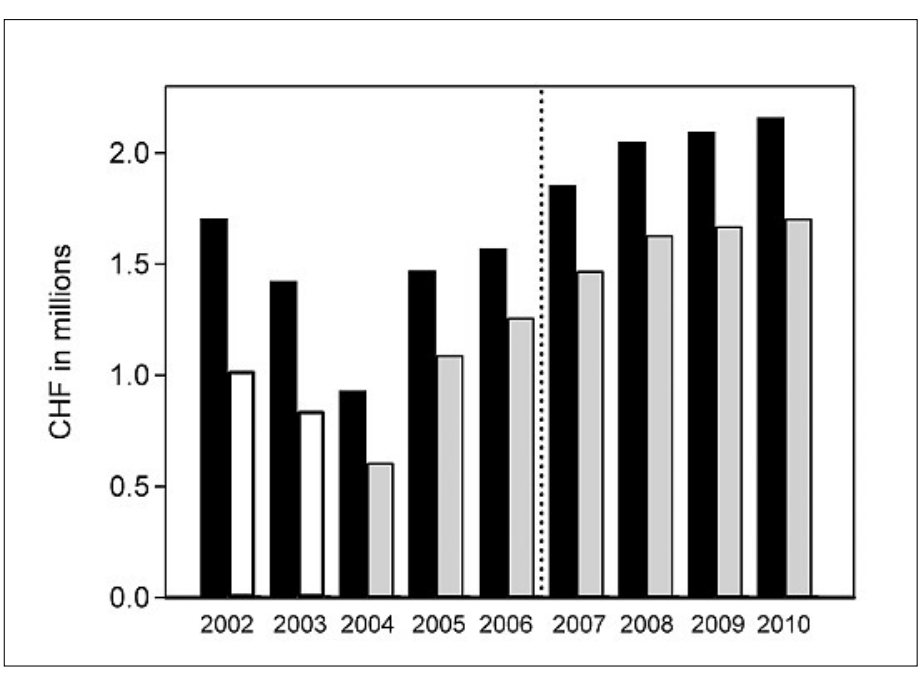

Fig. 5. Income from R\&D activities. The dashed line indicates the foundation of the Institute of Biotechnology in 2007 (formerly the Department of Biotechnology). The black bars show the total turnover of the Institute, the grey bars the proportion from R\&D, and the white bars provide rough estimates of the proportion from R\&D where exact figures are unavailable. students and lecturers, and the shared development of e-learning materials. The total revenue for all the universities involved in these Swiss-Czech projects since 1999 has now reached around 1,200,000 Euro. This amount can be expected to increase as in autumn 2006 the Swiss Federal Government passed a law making new funds available for the integration of eastern European countries into the European Union. ${ }^{[13]}$

Research groups from Austrian and Belgian universities with established MSc and $\mathrm{PhD}$ programmes have already been attracted by the scientific topic of our most recent projects, i.e. production technology for recombinant proteins with Pichia pastoris. To facilitate the process of becoming acquainted with these universities and promote discussion of further joint cooperation possibilities, ERASMUS agreements have been signed and the first students for diploma assignments exchanged. In addition, $\mathrm{PhD}$ students from various foreign universities have also been attracted to the UAS Wädenswil to take advantage of the advanced technical equipment available in order to carry out their research experiments. To maintain its appeal to foreign students, the UAS Wädenswil is continuously improving its equipment by adhering as far as possible to the principle that, for each research project acquired with a turnover of approx. CHF 1,000,000 or more, an up to CHF 100,000 investment in infrastructure is made. The benefits of this increasingly attractive infrastructure have recently been underscored by our coordinating the submission of an application to the Marie Curie Action 'People' of the 7th European FP for an Initial Training Network (INT) with academic and industry partners from Austria, Belgium, the Czech
Republic, Switzerland and the United Kingdom.

\subsection{Annual BioTech Conferences}

The first annual BioTech conference organised by the Institute of Biotechnology in Wädenswil took place some ten years ago and has since become an established tradition. Its initial aim was to bring alumni together to exchange experiences and expertise; it has now matured into an international scientific event.

Wide international attention was attracted by the themes of disposable technologies $^{[14]}$ and methylotrophic yeasts ${ }^{[15]}$ in 2005 and 2007 respectively. The BioTech conference in 2005[15] was held in Wädenswil together with the Swiss-Czech Symposium on Advanced Biotechnology, which Prague had previously hosted twice (in 1999 and 2002). Both events benefited from this synergy as a good many participants from academic institutions and industry attended. Indeed, European status was achieved and consequently the conferences are no longer viewed as merely either a local (Wädenswil) or a bilateral Swiss-Czech event. The 2008 Swiss-Czech Symposium will again be held in Switzerland and in 2011 in Prague. It is anticipated that these conferences will be further integrated into a comprehensive research training programme supported by the European Union.

\section{The Future: Lessons Learned}

Mutual scientific interests favour the first contacts with foreign partners and may lead directly to joint research projects. However, the importance of cooperations in educational matters (e.g. student exchange under the ERASMUS programme and/or sharing e-learning platforms) should not be underestimated during the first stages of new international partnerships. The considerable number of foreign universities willing to cooperate on research activities is a welcome confirmation of the high quality and international appeal of the $R \& D$ performed by the Institute of Biotechnology at the UAS Wädenswil. However, experience has shown that this proven bottom-up approach can be further strengthened in the following ways in order to expand and enhance our international activities:

i) To attract a wider range of foreign (and Swiss) university partners, the UASs should develop expertise in fields complementary to the main areas of interest of these potential partners. This would facilitate the more frequent publication of joint results and consequently create more favourable opportunities for successful fundraising as well as for recruiting and developing the careers of researchers at the UASs.

ii) As basic funding for research activities at UASs is currently very limited, a substantial supplementary amount should be available to assure the long-term continuation of international networks and to maintain distinct research directions.

iii) The introduction of Masters programmes is essential to allow the UASs to continue their research and further enhance its quality. This is also expected to impact positively on the current lack of incentive to pursue academic careers at the UASs.

iv) With the EUREKA label, increased promotion and enhanced funding for 
international projects is required by CTI alongside their primary function of supporting technology innovation and transfer within both universities and industry in Switzerland.

v) The joint development of teaching materials should be encouraged to stimulate the revision, coordination and harmonisation of curricula as well as of teaching methods at different higher education institutions on an international level.

vi) As acting internationally generally requires more precise and efficient communication over greater distances, further training in communication skills and the use of suitable software tools (e.g. a CMS used to develop e-learning materials) is required to facilitate knowledge transfer and management.

Each university of applied sciences in Switzerland continues to have its own international policy, and policies may even differ between individual departments and groups at the same institution. It is therefore evident that the extent and quality of international cooperations may vary. In January 2007 this hypothesis was supported in participant discussions at the Bürgenstock Conference, which focussed on internationalisation at UASs in Switzerland. ${ }^{[16]}$ Nonetheless, endeavours to increase the mobility of students, develop international programmes, and establish research and academic partnerships are ubiquitous. These activities could be beneficially facilitated by the establishment of centralised structures promoting the integration of universities into the European framework for higher education in an approved systematic way. However, a good deal of the future success will still depend on the scientific reputation of the persons involved and, thus, improving conditions for research at UASs is a prerequisite for enhancing their international impact.

\section{Acknowledgements}

We gratefully acknowledge the kind support of Karin Schuler, Petra Solenthaler and Nilay Karasahin, who collected the data evaluated and presented here. Our thanks are also extended to Robert Lovchik for his professional help in presenting the figures and to our colleagues Marco Bachmann, Mark Jäggi and Rolf Grabherr (all UAS Wädenswil) as well as Hans-Peter Meyer (Lonza AG) for critically reviewing the manuscript. Parts of this paper were presented at the 'Bürgenstock Konferenz der Schweizer Fachhochschulen'[16] on 19th January 2007 and some of the valuable input we gained in the ensuing discussions with participants has been included.

\section{Abbreviations and Glossary}

R\&D research and development

biotechLAB e-learning platform for teaching biotechnology launched by the UAS Wädenswil, http://www.biotechLAB.net

biotechnet biotechnet Switzerland, a network of Swiss Universities of Applied Sciences active in the field of biotechnology, http://www.biotechnet.ch CMS content management system CTI Commission of Technology and Innovation (i.e. the Swiss federal innovation promotion agency), http://www.bbt.admin.ch/kti

CzechInvest investment and business development agency of the Czech Republic, whose services and development programmes contribute to attracting foreign investment and to developing Czech companies,

http://www.czechinvest.org European Credit Transfer System, http://ec.europa.eu

ERASMUS European Community Action Scheme for the Mobility of University Students, http://ec.europa.eu

EUREKA a pan-European network for market-oriented, industrial research and development, http://www.eureka.be

IAESTE International Association for the Exchange of Students for Technical Experience,

http://www.iaeste.org

SVC Swiss Virtual Campus, an elearning initiative, $h t t p: / / w w w$. swissvirtualcampus.ch

UAS University of Applied Sciences

ZHAW Zurich University of Applied Sciences (abbreviation refers to the German name: Zürcher Hochschule für angewandte Wissenschaften)

Received: June 6, 2007
[1] B. Lepori, L. Attar, 'Research Strategies and Framework Conditions for Research in Swiss Universities of Applied Sciences', Lugano, 2006, p. 21-34.

[2] Bundesamt für Statistik, 'Studierende an den Fachhochschulen 2005/2006', Neuchâtel, 2006, p. 15-19.

[3] Bundesamt für Statistik, 'Der Geschäftsgang im sekundären Sektor', Neuchâtel, 2006.

[4] Bundesamt für Statistik, 'Taschenstatistik der Schweiz 2006', Neuchâtel, 2006, p. 12-13.

[5] BioWorld 'Biotechnet Beilage', 2006, 4.

[6] Transfer Spezial 'Hochschule Wädenswil', 2006.

[7] Konferenz der Fachhochschulen der Schweiz, 'Die Konzeption gestufter Studiengänge: Best Practice und Empfehlungen', Bern, 2004.

[8] Jahresbericht, Hochschule Wädenswil, 1999-2006.

[9] H.-P. Meyer, C. Ganter, Chimia 1999, 53, 525-565.

[10] K. Kovar, H.-P. Meyer, Chimia 2005, 59, 723-726.

[11] K. Kovar, T. K. Friedli, D. Roubicek, D. S. Langenegger, M. Keller, H.-P. Meyer, Chimia 2005, 59, 753-755.

[12] CzechInvest, 'Biotechnology company Lonza innovates its production in the Czech Republic', February 2007, http:// www.czechinvest.org/en/biotechnologycompany-lonza-innovates-its-productionin-the-czech-republic, Stand 2007-03-12.

[13] SR 974.1, Bundesgesetz über die Zusammenarbeit mit den Staaten Osteuropas, Bundesblatt 2006, 13, 3529-3536.

[14] BioTech 2007, http://www.biotech2007.ch

[15] 3rd Swiss-Czech Symposium on Advanced Biotechnology, http://www.swissczech.net

[16] Bürgenstock Konferenz der Schweizer Fachhochschulen, http://www.buergenstock-konferenz.ch 